\title{
Network-cost-loss-allocation methods evaluation under the perspective of the social welfare theory
}

\section{P.M. De Oliveira-De Jesus* and M.T. Ponce de Leão}

Electrical and Computer Department

Faculdade de Engenharia da Universidade do Porto (FEUP)

Instituto de Engenharia de Sistemas e Computadores (INESC Porto) Dr. Roberto Frias, 378 4200-465, Porto, Portugal

Fax: +35122 2094150

E-mail: pdeoliv@fe.up.pt

E-mail: mleao@fe.up.pt

*Corresponding author

\section{H.M. Khodr}

Instituto de Engenharia de Sistemas e Computadores (INESC Porto) Rua Dr. Roberto Frias, 378 4200-465, Porto, Portugal

Universidad Simòn Bolìvar

Valle de Satenejas

Caracas, Ap. 89000, Venezuela

Fax: +351222094150

E-mail: hkhodr@usb.ve

\begin{abstract}
Different ex post methodologies have been proposed to allocate network losses. Under day-ahead pool-based electricity markets, the implementation of these procedures implies an access-pricing framework based on half-hour or hourly locational prices. Since every allocation procedure modifies the locational prices in a different way, the initial market equilibrium point is altered as a result of the price elasticity of demand. This implies that some form of cross-subsidy appears among market agents, affecting economic variables as social welfare and network remuneration. This paper aims to contribute to the regulatory assessment by means of an analysis based on the social welfare theory in order to ensure a non-discriminatory access to the network. A base scenario is obtained through an optimal power flow study with the purpose of simulating an efficient energy market, and four allocation philosophies have been considered: incremental, roll-in-embedded, tracing based and circuit based. The methodology has been tested in two test cases: an illustrative three-bus network and the IEEE RTS 24-bus test network.
\end{abstract}

Keywords: electricity markets; loss allocation; power losses; power system economics; social welfare.

Reference to this paper should be made as follows: De Oliveira-De Jesus, P.M., Ponce de Leão, M.T. and Khodr, H.M. (2007) 'Network-cost-lossallocation methods evaluation under the perspective of the social welfare theory', Int. J. Global Energy Issues, Vol. 28, No. 1, pp.11-31. 
Biographical notes: P.M. De Oliveira-De Jesus received an MSc and Electrical Engineering degree in 2002 and 1995 from Universidad Simón Bolívar, Caracas, Venezuela. De Oliveira-De Jesus is pursuing PhD studies at Faculdade de Engenharia da Universidade do Porto (FEUP) and working as Researcher at Instituto de Engenharia de Sistemas e Computadores (INESC Porto), Portugal.

M.T. Ponce de Leão received her Electrical Engineering degree and $\mathrm{PhD}$ degree from Faculdade de Engenharia da Universidade do Porto (FEUP) in 1980 and 1996. Currently, she is Professor in the Electrical and Computer Department of FEUP. In 1987, she joined Instituto de Engenharia de Sistemas e Computadores (INESC Porto) as Researcher. In recent years, she was involved in the development of Distribution Management Systems (DMS) systems and the evaluation of the impact of distributed generation in distribution planning.

H.M. Khodr received his $\mathrm{PhD}$, MSc/Electrical Engineering degrees in Electrical Engineering from the José Antonio Echeverría Higher Polytechnic Institute (ISPJAE) in 1997 and 1993, respectively. He is currently Researcher at INESC Porto on leave from Universidad Simón Bolívar, Caracas, Venezuela. His current research activities are concentrated in the planning, operation and economics of electrical power systems.

\section{Introduction}

The tendency in the deregulation process is to turn electricity closer into a commodity to be traded in open-access markets. Under the pool-based market, an economically efficient solution requires the interaction of many buyers and sellers to yield a market clearing price equal to the cost of producing the last unit sold. Unfortunately, this interaction is achieved through an imperfect delivery network that produces power losses. The power injections of transmission and distribution systems are a combination of transactions between utilities, and the big issue is how to assign the cost of power losses among producers and consumers. To deal with this issue, several methodologies have been proposed in the literature (Conejo et al., 2002; Lima and Padilha-Feltrin, 2004; Salgado et al., 2004), to be applied as an ex post economic mechanism - losses regarded as an ancillary service - or through real-time or day-ahead hourly locational prices (Stoft, 2002). It is possible to identify at least four differentiated cost allocation philosophies: incremental, roll-in-embedded, tracing-based and circuit-based procedures.

The incremental procedures are based on the computation of Incremental Loss Factors (ILF) and can be obtained from an Optimal Power Flow (OPF) analysis (Schweppe et al., 1988) or using an AC power flow solution (Wood and Wollenberg, 1996; Elgerd, 1982). As a result of network non-linearities, ILF method produces an over-recovery of losses and some reconciled incremental procedures (R-ILF) have been suggested in Wu and Varaiya (1995) and Conejo et al. (2002). Also, as incremental methods are strongly dependent on the slack-bus designation, final solutions produce volatile positive or negative charges that are understood as a cross-subsidisation condition. To cope with this problem, an unsubsidised incremental method (U-ILF) has been proposed in Conejo et al. (2002). Other approaches were introduced to deal with the slack-bus designation by means of a distributed slack-load flow (Galiana et al., 2002) or 
based on the concept of centre of losses (Leite da Silva and Carvalho Costa, 2003). The pro rata $(\mathrm{PR})$ method establishes that losses are proportionally assigned to generators and consumers using average values, usually 50:50\% (Shrimohammadi et al., 1996). The proportional sharing (PS) procedure is based on the tracing of the power flow principle, assuming that power injections are proportionally shared among the outflows of each bus (Bialek, 1996). Finally, the circuit-based method uses the system impedance matrix (Zbus) to allocate losses in a nodal basis (Conejo et al., 2001).

In the last few years, an important debate has been raised about the fairness and arbitrariness of the loss allocation methodologies (Goméz Expósito et al., 2000). A number of studies devoted to comparing these procedures reveal a great variability in the results (Conejo et al., 2002; Lima and Padilha-Feltrin, 2004; Salgado et al., 2004).

These results have been discussed considering that ex post economic signals do not interfere with the technical functioning of the network (Conejo et al., 2002) and therefore load demand is considered inelastic or unresponsive to loss access prices.

However, independently of the arbitrariness or adequacy of a selected scheme, the authors consider that under day-ahead efficient markets, the loss allocation policy affects the load response. Since every allocation procedure modifies the hourly locational prices in a different way, depending on the philosophy, the market equilibrium is altered - as a result of the price elasticity of demand (De Oliveira-De Jesus and Ponce de Leão, 2004b; Schweppe et al., 1988), - and some form of cross-subsidy appears among market agents, affecting economic variables as the net social welfare and network remuneration.

Therefore, regulatory agencies must address the economic impact of the loss allocation methods in order to ensure a non-discriminatory access to the network. This paper aims to contribute to regulatory assessment by introducing a new method to evaluate the effect of each allocation procedure in an efficient energy market using the social welfare theory (Nicholson, 1997; Schweppe et al., 1988). The proposed analysis is applied in three steps:

1 Base scenario setup - simulation of an energy market through an Optimal Power Flow analysis

2 Development of an access-pricing framework using the four cost-loss-allocation philosophies: incremental, roll-in-embedded, tracing based and circuit based

3 Computation of a new equilibrium point for each allocation procedure, taking into account the effect of the elasticity at the demand side with the aim of evaluating social welfare and network remuneration level.

The methodology has been tested in two test cases, an illustrative three-node network and the IEEE RTS 24-bus network.

\section{Electricity market simulation using an optimal power flow}

As the first step in the proposed methodology, an OPF analysis simulates an efficient energy market to provide a base scenario or initial equilibrium point (Weber and Overbye, 1999). The OPF problem is stated here as the minimisation of the global social cost, described as the sum of all production costs minus all consumer benefits subject to the power balance equations and the capacity constraints. 
$\min \underbrace{\sum_{i=1}^{n} \operatorname{Cost}_{i}\left(P_{G i}\right)}_{\text {Production costs }}-\underbrace{\sum_{i=1}^{n} \operatorname{Benefit}_{i}\left(P_{D i}\right)}_{\text {Consumer benefit }}$

Subject to :

$P_{G}=P_{D}+L$

$P_{G i}-P_{D i}=V_{i} \sum_{j=1}^{n} V_{j}\left[G_{i j} \cos \theta_{i j}+B_{i j} \operatorname{sen} \theta_{i j}\right] i=1, \ldots, n$

$Q_{G i}-Q_{D i}=V_{i} \sum_{j=1}^{n} V_{j}\left[G_{i j} \operatorname{sen} \theta_{i j}-B_{i j} \cos \theta_{i j}\right] i=1, \ldots, n$

$P_{G i}^{\min } \leq P_{G i} \leq P_{G i}^{\max } i=1, \ldots, n$

$Q_{G i}^{\min } \leq Q_{G i} \leq Q_{G i}^{\max } i=1, \ldots, n$

$V_{i}^{\min } \leq V_{i} \leq V_{i}^{\max } i=1, \ldots, n$

$S_{L i j}^{\min } \leq S_{L i j} \leq S_{L i j}^{\max } i=1, \ldots, n \quad j=1, \ldots, n$

where:

$P_{G i}=$ active power output of generators of bus $i$

$P_{D i}=$ active power input of demands of bus $i$

$Q_{G i}=$ reactive power output of generators of bus $i$

$Q_{D i}=$ reactive power input of demands of bus $i$

$P_{G i}=$ active power output of generators of bus $i$

$P_{G}=$ total active power generated

$P_{D}=$ total active power demand

$L=$ total active power losses

$P_{G i}{ }^{\max }=$ maximum active power allowed of bus $i$

$P_{G i}{ }^{\text {min }}=$ minimum active power allowed of bus $i$

$Q_{G i}{ }^{\max }=$ maximum reactive power allowed of bus $i$

$Q_{G i}{ }^{m i n}=$ minimum reactive power allowed of bus $i$

$S_{L i j}=$ apparent power flow between bus $i$ and bus $j$

$S_{L i}{ }^{\max }=$ maximum power flow between bus $i$ and bus $j$

$S_{L i j}^{\text {min }}=$ maximum power flow between bus $i$ and bus $j$

$V_{i}, \theta_{I}=$ voltage and angle of bus $i$

$\theta_{i j}=$ difference between angles $i$ and $j$

$G_{i j}, B_{i j}=$ real and imaginary part of admittance matrix $Y$

$n, m=$ number of buses and branches. 
Since the consumer is included in the model as a market agent that is sensitive to changes in electricity prices, the consumer benefit function is obtained from a known linear demand curve, as shown in Figure 1, and applying the general definition (Nicholson, 1997):

$$
\operatorname{Benefit}_{i}\left(P_{D i}\right)=\int \rho_{D i}\left(P_{D i}\right) \cdot d P_{D i}=c_{i} P_{D i}-\frac{1}{2} d_{i} P_{D i}^{2} i, \ldots, n
$$

where:

$$
\rho_{D i}\left(P_{D i}\right)=c_{i}-d_{i} P_{D i} \quad i, \ldots, n
$$

Parameter $c$ corresponds to the maximum price the energy consumers is willing to pay. The slope of demand curve $d$ is obtained in the operating point $\left(\rho_{D}{ }^{o}, P_{D}{ }^{o}\right)$ from the price elasticity of the demand parameter:

$$
\varepsilon_{D i}=\frac{\Delta P_{D} / P_{D i}^{0}}{\Delta \rho / \rho_{D i}^{0}}=\frac{1}{d_{i}} \cdot \frac{\rho_{D i}^{0}}{P_{D i}^{0}} \quad i, \ldots, n
$$

On the other hand, production costs are known and expressed in a quadratic form (Wood and Wollenberg, 1996), as shown in Figure 1.

$$
\operatorname{Cost}_{i}\left(P_{G i}\right)=a_{i} P_{G i}+b_{i} P_{G i}^{2} \quad i, \ldots, n
$$

Then $a, b, c$ and $d$ coefficients characterise the behaviour of each market agent.

Figure 1 The demand and production curves
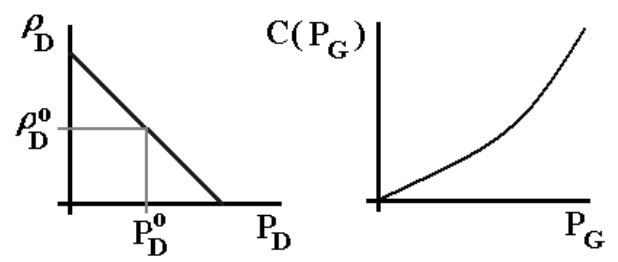

The solution to the optimisation problem stated in Equation (1) is composed of nodal voltages and angles, production outputs, demand consumptions, the system market price $\left(\lambda_{s y s}\right)$ and the Lagrange multipliers associated with the power balance constraints also known as the locational marginal prices $\left(\rho_{i}\right)$.

It is important to mention that if no capacity constraints are active (voltage, generation or capacity limits), the locational marginal prices provided by an OPF study originate a loss allocation strategy based on an incremental approach. Thus, ILF can be derived from the following decomposition formula (Schweppe et al., 1988):

$$
\rho_{i}=\rho_{D i}=\rho_{G i}=\lambda_{s y s}\left(1+\eta_{i}\right)+\sum \mu
$$

where $\eta_{i}$ is the Incremental Loss Factor associated with bus $i$. If capacity constraints (such as voltage, power generation or line flows) are not active, the congestion components of locational price $\Sigma \mu$ are equal to zero. 
Finally, the total power losses can be computed for the base scenario operating point using the following expression:

$$
L=\frac{1}{2} \sum_{i=1}^{n} \sum_{j=1}^{n} G_{i j}\left[V_{i}^{2}+V_{j}^{2}-2 V_{i} V_{j} \cos \theta_{i j}\right]
$$

\section{The access-pricing framework for network loss allocation}

The second step of the analysis proposed in this paper is the development of an access-pricing framework considering four cost allocation philosophies and six different loss allocation procedures. Despite the existence of many allocation procedures based upon an incremental formulation, only the fundamental incremental approaches (ILF, R-ILF and U-ILF) are considered in order to compare them with other allocation philosophies (Zbus, PR and PS). Further analyses with other incremental approaches could be considered as an avenue of investigation.

The pricing framework is based on day-ahead pool-based locational prices. For each consumer and producer, an additional charge in the energy price must be applied in order to recover the cost of active losses:

$$
\rho_{G i}=\lambda_{s y s}\left(1-K_{G i}\right) ; \quad \rho_{D i}=\lambda_{s y s}\left(1+K_{D i}\right) \quad i, \ldots, n
$$

where $K_{G i}$ and $K_{D i}$ are the loss allocation factors that can be expressed as a function of the power losses allocated $\left(L_{D i}\right.$ and $\left.L_{G i}\right)$ :

$$
K_{D i}=L_{D i} / P_{D i}, \quad K_{G i}=L_{G i} / P_{G i}
$$

Table 1 shows power losses to be allocated to each category and the loss allocation factors for each allocation procedure $k$. Positive loss allocations mean that market agents (producers or consumers) must be charged owing to the increase in losses. Conversely, negative charges mean that market agents must be compensated for the avoided losses.

The following is a summarised description of every procedure considered in this paper.

\subsection{Incremental allocation}

\subsubsection{Incremental Loss Factors (ILF)}

Incremental Loss Factors are sensitivity coefficients that measure the change in total power losses as a function of generation/consumption balance in each node.

$$
\eta_{i}=\partial L / \partial\left[P_{G i}-P_{D i}\right] \quad i, \ldots, n
$$

These factors are obtained at base operation point from the OPF Lagrange multipliers using Equation (6). 


\subsubsection{Reconciled Incremental Loss Factors (R-ILF)}

As a result of non-linearities of the network, the application of Incremental Loss Factors results in an overrecovery of power losses (De Oliveira-De Jesus and Ponce de Leão, 2004a). Then a normalisation procedure must be performed using a reconciliation factor $\kappa$.

$$
\kappa=\left|L /\left[\sum_{i=1}^{n} L_{G i}+\sum_{i=1}^{n} L_{D i}\right]\right|
$$

\subsubsection{Unsubsidised incremental allocation (U-ILF)}

Reconciled incremental factors, computed for a given slack bus, can be referred to a different slack bus by defining translation coefficient $\beta(0 \leq \beta \leq 1)$. Total losses can be computed as:

$$
L=\sum_{i=1}^{n}\left[\beta K_{i}+(1-\beta)\right]\left(P_{G i}-P_{D i}\right)=\sum_{i=1}^{n} K_{i}\left(P_{G i}-P_{D i}\right)
$$

The term $\beta K_{i}+(1-\beta)$ constitutes a new $K_{i}$ coefficient. The change of slack bus is performed in such a way that the generator and demand factors are recalculated using the smallest generator value $K_{G i}^{\min }$ and the highest demand value $K_{D i}{ }^{\max }$. This makes it impossible to assign negative losses to generators and loads.

$$
\beta_{G}=1 /\left(1-K_{G i}^{\min }\right) \quad \beta_{D}=1 /\left(1-K_{D i}^{\max }\right)
$$

Finally, unsubsidised incremental factors are again normalised in a pro rata form to allocate losses to generators and to loads using a 50:50\% proportion.

\subsection{Roll-in-embedded allocation (pro rata)}

The pro rata procedure uses average values to allocate losses among generators and loads using a 50:50\% proportion.

\subsection{Tracing-based allocation (proportional sharing)}

Proportional sharing methods are based on gross line flows. This method assumes that the system is fed with the actual generation, and then nodal generation remains unchanged but demands must be modified in order to accomplish Kirchoff's laws. An upstream-looking algorithm is applied to allocate losses among generators and a downstream-looking algorithm to allocate losses among loads using a 50:50\% proportion.

\subsection{Circuit-based allocation (Zbus)}

The circuit-based loss allocation model distributes the system losses $L$ among $n$ buses of the network according to the following:

$$
L=\sum_{i=1}^{n} L_{i}
$$


The $L_{i}$ components are obtained from the real part of the inverse of admittance matrix $Y=G+j B, Z b u s=Y^{-1}=R+j X$ through the following general expression:

$$
L_{i}=\mathfrak{R}\left[I_{i}^{*}\left(\sum_{j=1}^{n} R_{i j} I_{j}\right)\right] \quad i=1, \ldots, n
$$

where $I_{i}$ is the current injection at bus $i . L_{i}$ components are allocated at each bus among generators and loads using a 50:50\% proportion.

Table 1 Power losses allocated and loss allocation factors

\begin{tabular}{|c|c|c|c|c|c|c|}
\hline & \multicolumn{3}{|c|}{ Incremental } & $\begin{array}{l}\text { Roll-in- } \\
\text { embedded }\end{array}$ & Tracing-based & Circuit-based \\
\hline & $O P F$ & Reconciled & Unsubsidised & Pro rata & $\begin{array}{l}\text { Proportional } \\
\text { sharing }\end{array}$ & Zbus \\
\hline$k$ & 0 & 1 & 2 & 3 & 4 & 5 \\
\hline$L_{D i}$ & $-\eta_{i} P_{D i}$ & $-\kappa \eta_{i} P_{D i}$ & $\beta_{D} K_{i} P_{D i}+\left(1-\beta_{D}\right) P_{D i}$ & $0.5 L P_{G i} / P_{G}$ & $0.5\left(P_{D i}^{g r o s s}-P_{D i}\right)$ & $\frac{P_{D i}}{P_{G i}+P_{D i}} L_{i}$ \\
\hline$L_{G i}$ & $\eta_{i} P_{G i}$ & $\kappa \eta_{i} P_{G i}$ & $\beta_{G} K_{i} P_{G i}+\left(1-\beta_{G}\right) P_{G i}$ & $0.5 L P_{G i} / P_{G}$ & $0.5\left(P_{G i}^{g r o s s}-P_{G i}\right)$ & $\left(1-\frac{P_{D i}}{P_{G i}+P_{D i}}\right) L_{i}$ \\
\hline$K_{D i}$ & $-\eta_{i}$ & $-\kappa \eta_{i}$ & $\beta_{D} K_{i}+\left(1-\beta_{D}\right)$ & $0.5 L / P_{D}$ & $\frac{0.5\left(P_{D i}^{g r o s s}-P_{D i}\right)}{P_{D i}}$ & $\frac{L_{i}}{P_{G i}+P_{D i}}$ \\
\hline$K_{G i}$ & $\eta_{i}$ & $\kappa \eta_{i}$ & $\beta_{G} K_{i}+\left(1-\beta_{G}\right)$ & $0.5 L / P_{D}$ & $\frac{0.5\left(P_{G i}^{\text {gross }}-P_{G i}\right)}{P_{G i}}$ & $\left(1-\frac{P_{D i}}{P_{G i}+P_{D i}}\right) \frac{L_{i}}{P_{G i}}$ \\
\hline
\end{tabular}

\section{The social welfare analysis}

The third step and key idea held in this proposal is that efficient energy markets based on half-hour or hourly locational prices must comprise some elasticity at the demand side. Then, depending on the cost allocation procedure applied to assign losses, the equilibrium point is altered, affecting economic variables as social welfare and network remuneration. To achieve the impact of a given allocation procedure $k$, the proposed methodology is summarised in the block diagram as shown in Figure 2.

First, the OPF analysis described in Section 2 is performed in order to obtain the base scenario: optimum power losses $L$, power dispatch $\left(P_{D}{ }^{o}\right.$ and $\left.P_{G}{ }^{o}\right)$, locational marginal prices $\left(\rho^{o}\right)$, and the loss allocation factors $\left(K_{D i}{ }^{o}=\eta_{i}\right.$ and $\left.K_{G i}{ }^{o}=-\eta_{i}\right)$. The optimal losses $L$ achieved at base scenario are reallocated using the R-ILF, U-ILF, Zbus, PR and PS procedures. The pricing framework is applied using the allocation factors $K_{D i}{ }^{k}$ and $K_{G i}{ }^{k}$, as shown in Figure 2:

$$
\begin{gathered}
\rho_{D i}^{k}=\lambda_{s y s}\left(1+K_{D i}^{k}\right) \quad i=1, \ldots, n ; k=1, \ldots, 5 \\
\rho_{G i}^{k}=\lambda_{s y s}\left(1-K_{G i}^{k}\right) \quad i=1, \ldots, n ; k=1, \ldots, 5
\end{gathered}
$$


Figure 2 The social welfare and network remuneration evaluation

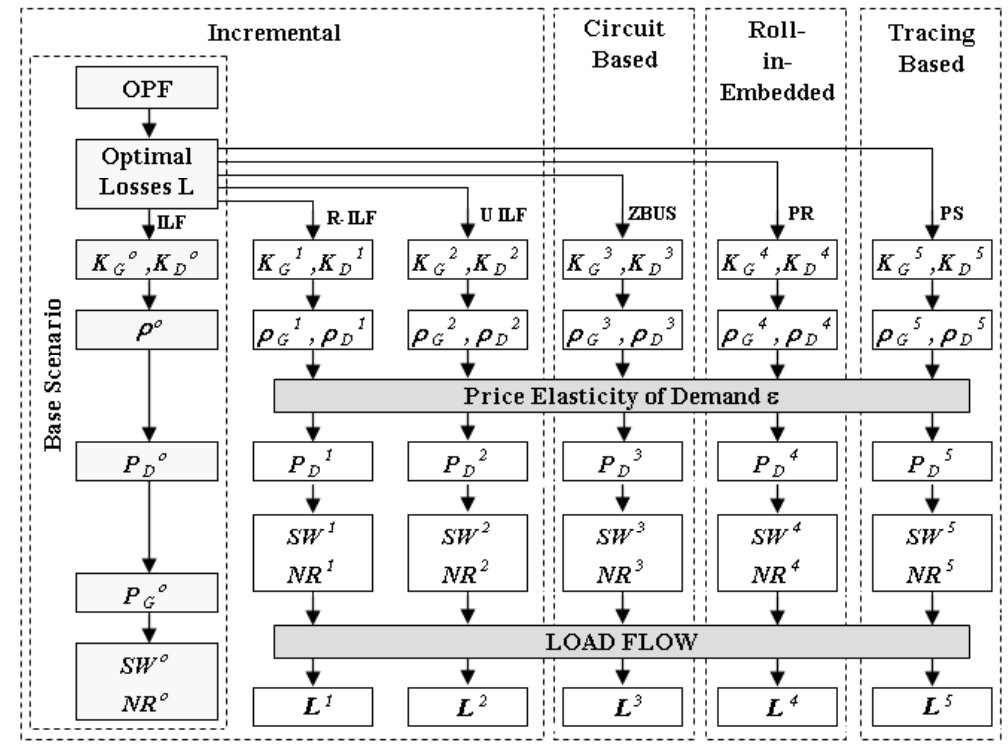

Finally, as shown in Figure 3, it is observed that the base scenario price $\rho_{D i}{ }^{o}$ is transformed into a new access price $\rho_{D i}{ }^{k}$, and then the load demand responds elastically, reaching a new consumption level $P_{D i}{ }^{k}$ given by:

$$
P_{D i}^{k}=\frac{c_{i}}{d_{i}}-\frac{1}{d_{i}} \rho_{D i}^{k} \quad i=1, \ldots, n ; k=1, \ldots, 5
$$

where $c_{i}$ and $d_{i}$ parameters are computed for each load associated with bus $i$ at a given elasticity parameter $\varepsilon_{D}$.

Figure 3 Base scenario and the new loss allocation operation point

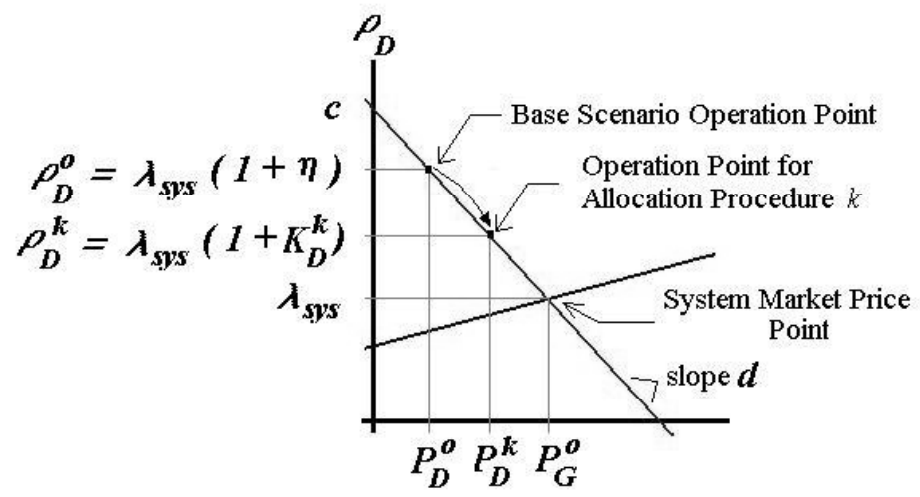


In agreement with the economic theory (Nicholson, 1997; Schweppe et al., 1988), the Social Welfare level $(S W)$ is computed at base scenario and all new equilibrium points as the sum of the producer surplus and the consumer surplus:

$$
S W^{k}=\overbrace{\underbrace{\sum_{i=1}^{n} \text { Benefit }_{i}^{k}}_{\text {Benefits }}-\underbrace{\sum_{i=1}^{n} \rho_{D i}^{k} P_{D i}^{k}}_{\text {Expenses }}}^{\text {Consumer surplus }}+\overbrace{\underbrace{\sum_{i=1}^{n} \rho_{G i}^{k} P_{G i}^{k}}_{\text {Revenues }}-\underbrace{\sum_{i=1}^{n} \operatorname{Cost}_{i}^{k}}_{\text {Costs }}}^{\text {Producer surplus }}
$$

where the consumer benefits (Benefit) and the production costs (Cost) are given by Equations (2) and (5), respectively.

Also, the Network Remuneration $(N R)$ is computed as the difference between the revenues and expenses:

$$
N R^{k}=\underbrace{\sum_{i=1}^{n} \rho_{D i}^{k} P_{D i}^{k}}_{\text {Revenues }}-\underbrace{\sum_{i=1}^{n} \rho_{G i}^{k} P_{G i}^{k}}_{\text {Expenses }}
$$

The evaluation method is a one-round analysis because the power dispatch remains unaltered. Generators are previously dispatched (for instance, day-ahead markets) and cannot change their profile when locational prices are communicated to consumers. Thus, for each new equilibrium point a load flow analysis must be made in order to calculate the power losses $\left(L^{k}\right)$ incurred in the system due to changes at the demand side.

\section{Test cases}

The proposed methodology has been tested in two cases, first an illustrative three-bus test network and next using the IEEE 24-Bus Reliability Test System (RTS) (IEEE APM Subcommittee, 1979). Systems are assumed to be a single energy market. The optimal power flow analysis, the selected loss allocation procedures and the load flow studies have been programmed and performed using the MATLAB platform.

\subsection{Case No. 1: Three-bus network}

The one-line diagram and line data of a three-bus test case is shown in Figure 4.

Figure 4 Three-bus test network

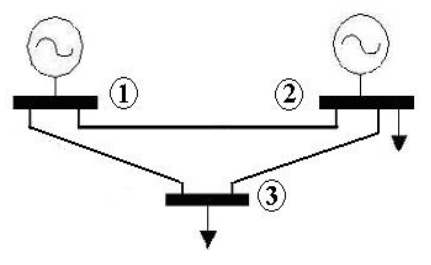

\begin{tabular}{ccccc}
\hline & $R$ & $X$ & $B_{C A P}$ & $S_{\max }$ \\
\cline { 2 - 5 } Line & \multicolumn{4}{c}{$p u$} \\
\hline $1-2$ & 0.05 & 1 & 0.02 & 1 \\
$2-3$ & 0.05 & 1 & 0.02 & 1 \\
$1-3$ & 0.05 & 1 & 0.02 & 1 \\
\hline S $_{\text {BASE }}=$ & $10 \mathrm{MVA}$ & \multicolumn{2}{c}{$\mathrm{V}_{\text {BASE }}=10 \mathrm{kV}$}
\end{tabular}


Line data specification is given using $\mathrm{S}_{\mathrm{BASE}}=10 \mathrm{MVA}$ and $\mathrm{V}_{\mathrm{BASE}}=10 \mathrm{kV}$. In order to perform the OPF analysis, production cost functions were set as $\operatorname{Cost}_{1}\left(P_{G 1}\right)=10 P_{G 1}$ and $\operatorname{Cost}_{2}\left(P_{G 2}\right)=10 P_{G 2}+0.4 P_{G 2}{ }^{2}$. The demand curves associated with $P_{D 2}$ and $P_{D 3}$ were built considering a price elasticity equal to -0.5 at the equilibrium points $(10.248 \$ / \mathrm{MWh}$, $2 \mathrm{MW}$ ) and (10.324\$/MWh, 3.5 MW), respectively. This means that in all buses a $20 \%$ reduction in the energy price will cause a demand increase of $10 \%$. Demand functions were written as $\rho_{D 2}=30.746-10.248 P_{D 2}$ and $\rho_{D 3}=30.978-5.899 P_{D 3}$. Then, using Equation (2), benefit functions are written as Benefit $\left(P_{D 2}\right)=30.746 P_{D 2}-5.124 P_{D 2}{ }^{2}$ and Benefit $\left(P_{D 3}\right)=30.978 P_{D 3}-2.949 P_{D 3}{ }^{2}$. No reactive loads were considered in this example.

\subsubsection{Base scenario equilibrium point}

The OPF problem stated in Section 2 was performed considering bus 1 as the slack or reference bus. Voltage level at buses 1 and 2 were set at $1.0 \mathrm{pu}$. The results are indicated in Table 2.

Table 2 Optimal power flow solution - three-bus test case

\begin{tabular}{lccc}
\hline Bus & $V[\mathrm{pu}]$ & $\theta[\mathrm{rad}]$ & Lagrange multipliers $[\$ / \mathrm{MWh}]$ \\
\hline 1 & 1.0000 & 0 & 10.00000 \\
2 & 1.0000 & -0.2363 & 10.24880 \\
3 & 0.9775 & -0.2999 & 10.32395 \\
\hline
\end{tabular}

The equilibrium point is reached when $P_{G 1}=5.26 \mathrm{MW}, P_{G 2}=0.31 \mathrm{MW}, P_{D 2}=2 \mathrm{MW}$ and $P_{D 3}=3.5 \mathrm{MW}$. No congestion was achieved in capacity constraints. System market price $\lambda_{\text {sys }}$ is equal to $10 \$ / \mathrm{MWh}$ and the power losses $L$ are $73.73 \mathrm{~kW}$. At equilibrium point, competitive locational marginal prices are $\rho_{D 1}{ }^{o}=10 \$ / \mathrm{MWh}, \rho_{D 2}{ }^{o}=10.248 \$ / \mathrm{MWh}$ and $\rho_{D 3}{ }^{\circ}=10.324 \$ / \mathrm{MWh}$.

\subsubsection{Power loss allocation}

Tables 3 and 4 provide the percentage of total losses allocated to generators and loads - calculated as $100 \% x L_{G i} / L$ and $100 \% x L_{D i} / L$ - using the results of the OPF analysis (ILF) and the R-ILF, U-ILF, Zbus, PR and PS allocation procedures.

Table 3 Optimal percentage of losses allocated to generators

\begin{tabular}{lrcccrr}
\hline \multirow{2}{*}{$\begin{array}{l}\text { Generator } \\
\text { bus }\end{array}$} & $I L F(\%)$ & $R$-ILF $(\%)$ & $U-I L F(\%)$ & ZBUS $(\%)$ & $P R(\%)$ & $P S(\%)$ \\
\cline { 2 - 7 } 1 & 0.00 & 0.00 & 50.00 & 63.77 & 47.21 & 49.82 \\
2 & -10.49 & -4.98 & 0.00 & 0.95 & 2.79 & 0.18 \\
Total & -10.49 & -4.98 & 50.00 & 64.72 & 50.00 & 50.00 \\
\hline
\end{tabular}


Table 4 Percentage of losses allocated to loads

\begin{tabular}{lrccccc}
\hline & \multicolumn{7}{c}{ Procedures } \\
\cline { 2 - 7 } Load bus & $I L F(\%)$ & $R$-ILF $(\%)$ & U-ILF $(\%)$ & ZBUS $(\%)$ & PR $(\%)$ & PS (\%) \\
\hline 2 & 67.48 & 32.02 & 15.25 & 6.11 & 18.18 & 14.28 \\
3 & 153.76 & 72.96 & 34.75 & 29.18 & 31.82 & 35.72 \\
Total & 221.23 & 104.98 & 50.00 & 35.28 & 50.00 & 50.00 \\
\hline
\end{tabular}

The optimal access-pricing framework obtained from the OPF analysis (ILF) produces a loss sharing proportion of 221:-10.5\% among loads and generators achieving an overrecovery of losses, approximately $210 \%$. Also, the results show that all loads and generators must pay for power losses, except generator 2 , which is rewarded with $-10.5 \%$ and $-5 \%$ of losses in ILF and R-ILF procedures, respectively. As shown in Figure 5, under the ILF procedure, load 3 is charged with very high values and generator 2 is allocated negative values. This means that load 3 is charged for its contribution in power loss increase and generator 2 is compensated for its contribution in loss reduction.

The R-ILF procedure demonstrates less volatile behaviour than ILF, assigning positive and negative losses to loads and to generators through a 105:-5\% allocation proportion. The U-ILF allocates positive losses for all loads and generators. The slack bus must be translated from bus 1 to bus 2 . It is relevant to point out that U-ILF, PR and PS procedures allocate power losses in an arbitrary 50:50\% proportion. Finally, the Zbus procedure allocates losses in a 35.3:64.7\% proportion.

Figure 5 Percentage of losses allocated to generators and loads
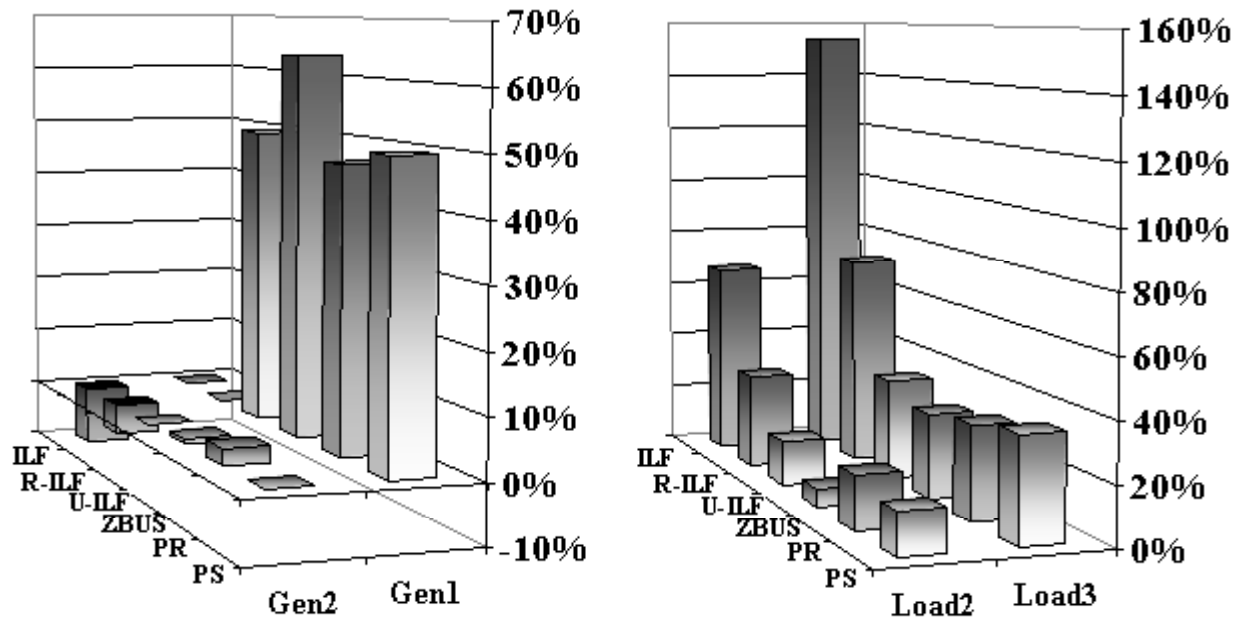

\subsubsection{Access-pricing framework and social welfare evaluation}

As demand behaviour is dependent on energy prices, after the application of every loss allocation procedure, new access prices and demand consumptions are obtained by applying Equations (16-18). In Table 5, the ILF solution is presented and five new operation points are computed for each allocation procedure. 
Table 5 Equilibrium point for OPF solution and new operation points for the five loss allocation procedures

\begin{tabular}{lccccccccc}
\hline \multirow{2}{*}{$\begin{array}{l}\text { Loss } \\
\text { allocation } \\
\text { procedures }\end{array}$} & \multicolumn{2}{c}{ Production } & \multicolumn{2}{c}{ Demand } & Losses & \multicolumn{4}{c}{ Nodal prices } \\
\cline { 2 - 10 } & $P_{G 1}$ & $P_{G 2}$ & $P_{D 2}$ & $P_{D 3}$ & $L$ & $\rho_{G 1}$ & $\rho_{G 2}$ & $\rho_{D 2}$ & $\rho_{D 3}$ \\
\hline ILF & 0.526 & 0.031 & 0.200 & 0.350 & 73.7 & 10.000 & 10.249 & 10.249 & 10.324 \\
R-ILF & 0.531 & 0.031 & 0.201 & 0.353 & 75.0 & 10.000 & 10.118 & 10.118 & 10.154 \\
U-ILF & 0.533 & 0.031 & 0.202 & 0.354 & 75.6 & 9.930 & 10.000 & 10.056 & 10.073 \\
ZBUS & 0.533 & 0.031 & 0.202 & 0.354 & 75.7 & 9.911 & 9.977 & 10.023 & 10.061 \\
PR & 0.533 & 0.031 & 0.202 & 0.354 & 75.6 & 9.934 & 9.934 & 10.067 & 10.067 \\
PS & 0.533 & 0.031 & 0.202 & 0.354 & 75.6 & 9.930 & 9.996 & 10.053 & 10.075 \\
\hline
\end{tabular}

The results indicate that all solutions produce locational prices lower than ILF prices. These conditions encourage an increase in load consumption as a consequence of the responsiveness of demand, and maximum power losses are obtained under the pro rata approach. It is important to point out that the lowest power losses are achieved under the OPF approach (ILF).

Network expenses, revenues and remuneration results are presented in Table 6. Table 7 summarises consumer surplus, producer surplus and social welfare level.

Table 6 Three-bus network remuneration

\begin{tabular}{lccc}
\hline & \multicolumn{3}{c}{ Network } \\
\cline { 2 - 4 } $\begin{array}{l}\text { Loss allocation } \\
\text { procedure }\end{array}$ & Expenses & Revenues & Remuneration \\
\cline { 2 - 4 } ILF & 55.81 & 56.63 & \\
R-ILF & 56.20 & 56.20 & 0.8165 \\
U-ILF & 56.00 & 55.99 & -0.0066 \\
ZBUS & 55.94 & 55.93 & -0.0100 \\
PR & 56.00 & 55.99 & -0.0107 \\
PS & 56.00 & 55.99 & -0.0104 \\
\hline
\end{tabular}

Table 7 Social welfare, producer and consumer surplus

\begin{tabular}{lccccccc}
\hline \multirow{2}{*}{$\begin{array}{l}\text { Loss } \\
\begin{array}{l}\text { allocation } \\
\text { procedure }\end{array}\end{array}$} & \multicolumn{5}{c}{ Producer } & \multicolumn{5}{c}{ Consumer } & \multirow{2}{*}{$\begin{array}{c}\text { Social } \\
\text { welfare }\end{array}$} \\
\cline { 2 - 6 } & Revenues & Costs & Surplus & Expenses & Benefits & Surplus & \\
\hline ILF & 55.81 & 55.78 & 0.04 & 56.63 & 113.26 & 56.63 & 56.670 \\
R-ILF & 56.20 & 56.20 & 0.00 & 56.20 & 113.69 & 57.49 & 57.489 \\
U-ILF & 56.00 & 56.41 & -0.41 & 55.99 & 113.89 & 57.90 & 57.489 \\
ZBUS & 55.94 & 56.46 & -0.52 & 55.93 & 113.94 & 58.01 & 57.488 \\
PR & 56.00 & 56.41 & -0.41 & 55.99 & 113.89 & 57.90 & 57.489 \\
PS & 56.00 & 56.41 & -0.41 & 55.99 & 113.89 & 57.90 & 57.489 \\
\hline
\end{tabular}


In all new equilibrium points, the allocation procedures produce negative network remuneration at the same social welfare level. It is observed that the R-ILF procedure reaches the lowest network remuneration value, ensuring revenue reconciliation of $99 \%$ of system power losses.

Its relevant to point out that consumer surplus is always positive for all allocation methods. However, producer surplus is negative when U-ILF, Zbus, PR and PS approaches are used.

At base scenario, the price strategy obtained from an OPF analysis (ILF) produces an overrecovery of power losses and positive network remuneration $(0.8165 \$ / \mathrm{h})$ affecting the social welfare level $(56.67 \$ / \mathrm{h})$. This condition means that a transmission network provider receives earnings through system losses. This result may be the object of discussion. In agreement with the economic theory, social welfare function (Equation (19)) is a measure of social benefit, considering only producers and consumers as market agents. In this expression, the transmission provider is not expressly included as a market agent because as a monopolist his marginal remuneration must be equal to zero. The profit of the network provider is recognised by the regulatory board by way of a reasonable rate of return of invested capital and no earnings due to losses must be admitted.

\subsection{Case No. 2: 24-bus network}

The IEEE Reliability Test System (RTS) (IEEE APM Subcommittee, 1979) was used to apply the proposed methodology. The system has 24 buses, 38 circuits and ten power-generating plants. Installed capacity is $3405 \mathrm{MW}$.

\subsubsection{Base scenario equilibrium point}

The OPF analysis was performed taking into account that the economical data was given at peak load condition and the power generation limits indicated in the Appendix. Voltage level limits were set between $95 \%$ and $105 \%$. Bus 13 was considered the slack bus. The results of OPF analysis are shown in Table 8 .

Table 8 Optimal power flow solution - 24-bus test case

\begin{tabular}{lccccccc}
\hline & $\begin{array}{c}\text { Voltage } \\
\text { level }\end{array}$ & Angle & $\begin{array}{c}\text { Lagrange } \\
\text { multiplier }\end{array}$ & & $\begin{array}{c}\text { Voltage } \\
\text { level }\end{array}$ & Angle & $\begin{array}{c}\text { Lagrange } \\
\text { multiplier }\end{array}$ \\
\cline { 2 - 4 } & $p u$ & rad & $\$ / M W h$ & Bus & $p u$ & rad & $\$ / M W h$ \\
\hline 1 & 0.9928 & -0.066 & 26.50 & 13 & 1.0094 & 0.000 & 27.00 \\
2 & 0.9904 & -0.067 & 26.51 & 14 & 1.0086 & 0.053 & 26.64 \\
3 & 0.9745 & -0.065 & 26.65 & 15 & 1.0500 & 0.211 & 25.55 \\
4 & 0.9648 & -0.130 & 27.54 & 16 & 1.0485 & 0.191 & 25.68 \\
5 & 0.9959 & -0.131 & 27.36 & 17 & 1.0488 & 0.269 & 25.17 \\
6 & 1.0500 & -0.192 & 27.89 & 18 & 1.0500 & 0.294 & 25.01 \\
7 & 1.0140 & -0.065 & 26.50 & 19 & 1.0414 & 0.165 & 25.86 \\
8 & 0.9808 & -0.147 & 27.72 & 20 & 1.0449 & 0.176 & 25.79 \\
9 & 0.9795 & -0.103 & 27.20 & 21 & 1.0500 & 0.308 & 24.91 \\
10 & 1.0280 & -0.139 & 27.36 & 22 & 1.0500 & 0.406 & 24.29 \\
11 & 1.0023 & -0.024 & 27.16 & 23 & 1.0500 & 0.194 & 25.67 \\
12 & 1.0059 & -0.015 & 27.12 & 24 & 1.0072 & 0.112 & 26.28 \\
\hline
\end{tabular}


The solution is reached when the objective function is equal to $92.21 \$ / \mathrm{hr}$. System market price $\lambda_{\text {sys }}$ is equal to $27 \$ / \mathrm{MWh}$ and optimal dispatch is shown in Table 9. Losses to be allocated are equal to $52.4 \mathrm{MW}$.

Table 9 Optimal dispatch - 24-bus test case

\begin{tabular}{|c|c|c|c|c|c|c|c|}
\hline & $P_{G}^{\circ}$ & $P_{D}^{\circ}$ & $Q_{D}^{\circ}$ & & $P_{G}^{\circ}$ & $P_{D}^{\circ}$ & $Q_{D}^{\circ}$ \\
\hline Bus & $M W$ & $M W$ & $M V A r$ & Bus & $M W$ & $M W$ & $M V A r$ \\
\hline 1 & 192.0 & 108.0 & 22.0 & 13.0 & 112.6 & 265.0 & 54.0 \\
\hline 2 & 192.0 & 97.0 & 20.0 & 14.0 & - & 194.0 & 39.0 \\
\hline 3 & - & 180.0 & 37.0 & 15.0 & 227.0 & 317.0 & 64.0 \\
\hline 4 & - & 74.3 & 15.0 & 16.0 & 155.0 & 100.0 & 20.0 \\
\hline 5 & - & 71.0 & 14.0 & 18.0 & 400.0 & 333.0 & 68.0 \\
\hline 6 & - & 136.0 & 28.0 & 19.0 & - & 181.0 & 37.0 \\
\hline 7 & 264.1 & 125.0 & 25.0 & 20.0 & - & 128.0 & 26.0 \\
\hline 8 & - & 171.0 & 35.0 & 21.0 & 400.0 & - & - \\
\hline 9 & - & 175.0 & 36.0 & 22.0 & 300.0 & - & - \\
\hline 10 & - & 195.0 & 40.0 & 23.0 & 660.0 & - & - \\
\hline
\end{tabular}

\subsubsection{Power loss allocation}

Tables 10 and 11 provide the percentage of total losses allocated to generators and loads using the results of the OPF analysis (ILF) and the R-ILF, U-ILF, Zbus, PR and PS allocation procedures. In general, all generators must pay for power losses. In contrast, loads or demands are rewarded under ILF and R-ILF approaches. Under U-ILF, PR and PS procedures, all loads and generators must pay for losses.

Table 10 Percentage of losses allocated to generators

\begin{tabular}{lrrcccc}
\hline \multirow{2}{*}{$\begin{array}{l}\text { Generator } \\
\text { bus }\end{array}$} & \multicolumn{7}{c}{ Procedures } \\
\cline { 2 - 6 } & $I L F(\%)$ & $R$-ILF $(\%)$ & $U$-ILF $(\%)$ & ZBUS $(\%)$ & $P R(\%)$ & $P S(\%)$ \\
\hline 1 & 6.79 & 3.58 & 1.15 & 0.71 & 3.31 & 1.38 \\
2 & 6.60 & 3.48 & 1.12 & 1.24 & 3.31 & 3.01 \\
7 & 9.40 & 4.96 & 1.59 & 1.06 & 4.55 & 2.94 \\
13 & 0.00 & 0.00 & 0.00 & 0.20 & 1.94 & 0.27 \\
15 & 23.30 & 12.30 & 3.94 & -1.65 & 3.91 & 2.29 \\
16 & 14.49 & 7.65 & 2.45 & 1.78 & 2.67 & 2.60 \\
18 & 56.30 & 29.71 & 9.53 & 2.51 & 6.89 & 4.19 \\
21 & 58.95 & 31.11 & 9.98 & 28.65 & 6.89 & 7.89 \\
22 & 57.44 & 30.31 & 9.72 & 28.28 & 5.17 & 10.98 \\
23 & 62.22 & 32.83 & 10.53 & 29.30 & 11.37 & 14.46 \\
Total & 295.50 & 155.93 & 50.00 & 92.07 & 50.00 & 50.00 \\
\hline
\end{tabular}


Table 11 Percentage of losses allocated to loads

\begin{tabular}{lrrrrrr}
\hline \multirow{2}{*}{ Generator } & \multicolumn{5}{c}{ Procedures } \\
\cline { 2 - 6 } bus & $I L F(\%)$ & $R$-ILF $(\%)$ & $U$-ILF $(\%)$ & ZBUS $(\%)$ & $P R(\%)$ & $P S(\%)$ \\
\hline 1 & -3.82 & -2.01 & 1.93 & 0.40 & 1.89 & 0.00 \\
2 & -3.34 & -1.76 & 1.75 & 0.63 & 1.70 & 0.00 \\
3 & -4.42 & -2.33 & 3.54 & -1.17 & 3.16 & 5.19 \\
4 & 2.84 & 1.50 & 2.25 & 2.09 & 1.30 & 1.88 \\
5 & 1.80 & 0.95 & 2.00 & 1.56 & 1.25 & 1.48 \\
6 & 8.52 & 4.49 & 4.68 & 4.86 & 2.39 & 6.43 \\
7 & -4.45 & -2.35 & 2.23 & 0.50 & 2.19 & 0.00 \\
8 & 8.68 & 4.58 & 5.55 & 5.57 & 3.00 & 4.72 \\
9 & 2.52 & 1.33 & 4.60 & 2.25 & 3.07 & 5.89 \\
10 & 4.95 & 2.61 & 5.49 & 3.59 & 3.42 & 6.61 \\
13 & 0.00 & 0.00 & 6.32 & 0.46 & 4.65 & 4.38 \\
14 & -4.90 & -2.59 & 3.79 & -1.69 & 3.40 & 6.02 \\
15 & -32.54 & -17.17 & 2.05 & -2.31 & 5.56 & 3.20 \\
16 & -9.35 & -4.93 & 0.80 & 1.15 & 1.75 & 1.30 \\
18 & -46.87 & -24.73 & 0.00 & 2.09 & 5.84 & 0.40 \\
19 & -14.64 & -7.72 & 1.84 & -6.88 & 3.18 & 2.20 \\
20 & -10.97 & -5.79 & 1.19 & -5.17 & 2.25 & 0.30 \\
Total & -105.98 & -55.93 & 50.00 & 7.93 & 50.00 & 50.00 \\
\hline & & & & & & \\
\hline
\end{tabular}

The optimal access-pricing framework (ILF) produced a loss sharing of $-106: 295.5 \%$ among loads and generators achieving an overrecovery of $190 \%$. The R-ILF recovered the entire losses with less volatile behaviour $(-56: 156 \%)$. The U-ILF, pro rata and proportional sharing methods always resulted in positive losses (50:50\%). The U-ILF method required a translation of the slack bus from bus 13 to bus 18 . The Zbus allocation produces positive charges and some negative losses (8:92\%).

\subsubsection{Access-pricing framework and social welfare evaluation}

Unlike the three-bus test case, a high price variability was observed in all allocation procedures, as seen in Figure 6.

The social welfare evaluation was performed considering a price elasticity of demand equal to -0.5 in all demand buses (corresponding to peak load). Table 12 shows the results of total power losses incurred and network remuneration: expenses and revenues. Table 13 details the social welfare level, the producer and consumer surplus.

The lowest power losses were achieved under the ILF procedure and the maximum under the PR approach. Also, the ILF strategy produced positive network remuneration $(1266 \$ / \mathrm{h})$ representing an overrecovery of power losses of $190 \%$. The R-ILF, U-ILF, Zbus, PR and PS procedures recovered 98.0\%, 90.2\%, 92.2\%, 86.7\% and 89.9\% of total power losses, respectively. As shown in Figure 7, all procedures - except ILF - generated negative network remuneration, implying an under-recovery of losses. It 
was observed that the R-ILF procedure ensures the best value of network remuneration $(98 \%)$ and the PR procedure is the worst approach $(89.9 \%)$. Also, under this last approach was obtained the highest value of power losses incurred in the system.

Figure 6 Energy prices at consumption nodes for each allocation procedure

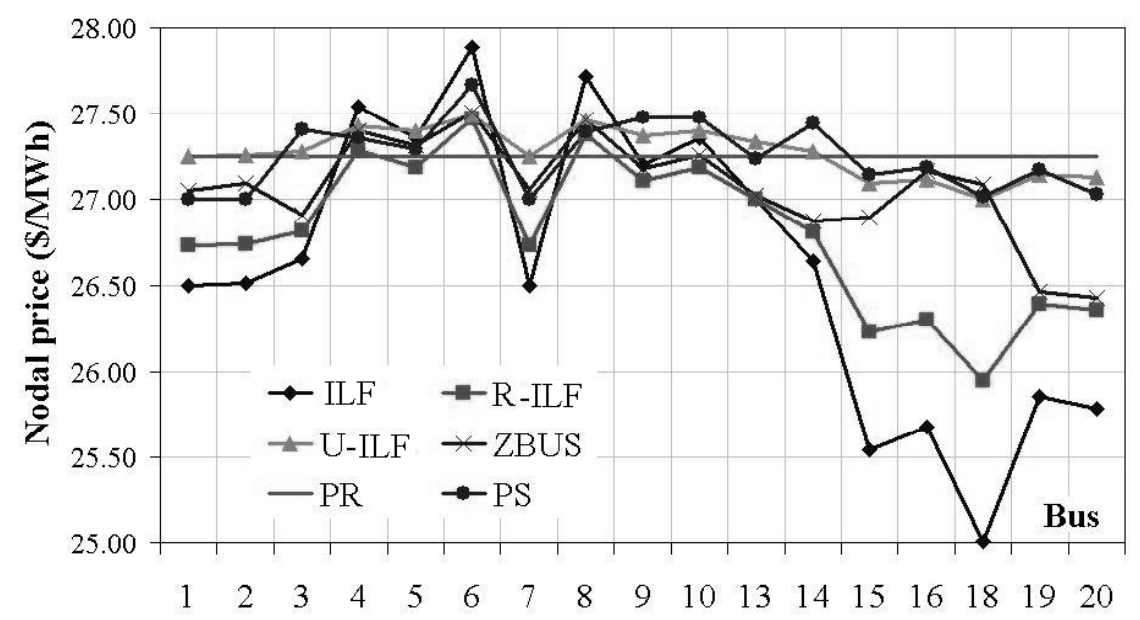

Table 12 24-bus network remuneration

\begin{tabular}{lcccc}
\hline & & \multicolumn{3}{c}{ Transmission network } \\
\cline { 3 - 5 } $\begin{array}{l}\text { Loss allocation } \\
\text { procedure }\end{array}$ & \begin{tabular}{c} 
Power losses \\
\cline { 3 - 5 }
\end{tabular} & MW & \multicolumn{3}{c}{ Expenses } & Revenues & Remuneration \\
\hline ILF & 52.40 & 74.19 & 75.46 & $(\$ / h r)$ \\
R-ILF & 53.44 & 75.81 & 75.80 & 1266.51 \\
U-ILF & 54.66 & 76.57 & 76.50 & -13.39 \\
ZBUS & 54.39 & 76.27 & 76.22 & -65.52 \\
PR & 54.94 & 76.58 & 76.49 & -52.13 \\
PS & 54.66 & 76.57 & 76.50 & -89.10 \\
\hline
\end{tabular}

Table 13 Social welfare, producer and consumer surplus

\begin{tabular}{|c|c|c|c|c|c|c|c|}
\hline \multirow{3}{*}{$\begin{array}{l}\text { Loss } \\
\text { allocation } \\
\text { procedure }\end{array}$} & \multicolumn{3}{|c|}{ Producer } & \multicolumn{3}{|c|}{ Consumer } & \multirow{3}{*}{$\begin{array}{c}\text { Social } \\
\text { welfare }\end{array}$} \\
\hline & Revenues & Costs & Surplus & Expenses & Benefits & Surplus & \\
\hline & \multicolumn{6}{|c|}{ (Thousand \$/hr) } & \\
\hline ILF & 74.19 & 58.72 & 15.48 & 75.46 & 150.92 & 75.46 & 90.93 \\
\hline R-ILF & 75.81 & 58.36 & 17.45 & 75.80 & 150.56 & 74.76 & 92.21 \\
\hline U-ILF & 76.57 & 57.62 & 18.95 & 76.50 & 149.78 & 73.28 & 92.23 \\
\hline ZBUS & 76.27 & 57.91 & 18.35 & 76.22 & 150.09 & 73.87 & 92.23 \\
\hline PR & 76.58 & 57.62 & 18.96 & 76.49 & 149.78 & 73.29 & 92.25 \\
\hline PS & 76.57 & 57.62 & 18.95 & 76.50 & 149.78 & 73.28 & 92.23 \\
\hline
\end{tabular}


Figure 7 Social welfare and network remuneration

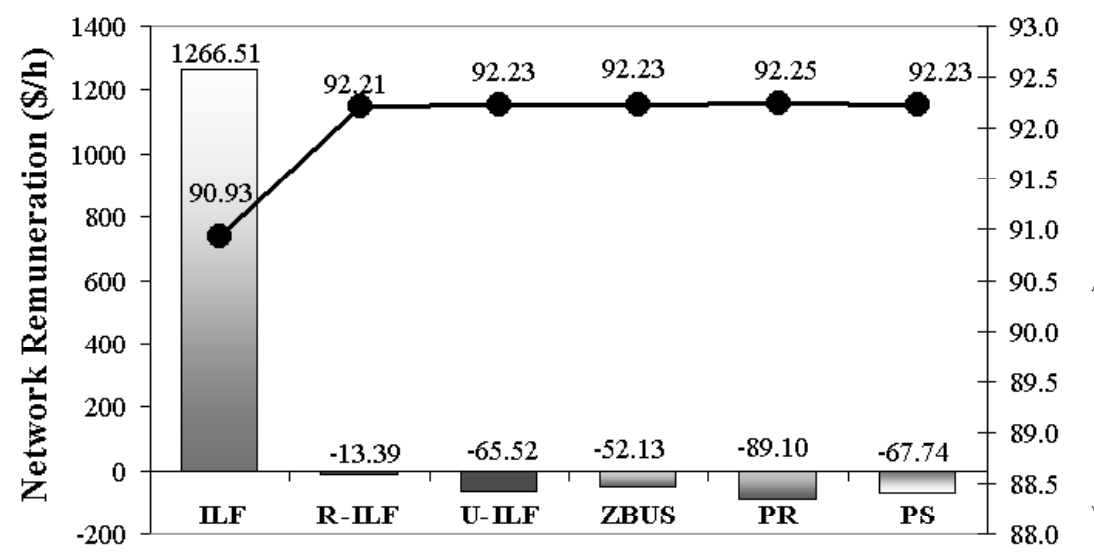

Finally, as an important result, we observed that social welfare is not affected under all reconciled procedures. In particular, if we compare R-ILF (bus 13) and U-ILF (bus 18) results, it is seen that the slack-bus choice does not affect social welfare.

\subsubsection{Sensitivity analysis}

With the intention of verifying the fairness of the proposed methodology, a sensitivity analysis was performed considering the solutions for IEEE RTS applying different elasticity values among -0.1 (very inelastic) and -4 (very elastic).

Results confirm the same trend shown in both test cases studied. Locational prices obtained from OPF analysis (ILF) always recover approximately twice the power losses caused in the system at the minimum power loss level. The R-ILT, U-ILF, Zbus, PR and PS approaches always present under-recovery of losses.

\subsubsection{Final discussion}

In our point of view, network access-pricing design in liberalised energy markets must take into account the effect of price elasticity of demand. Therefore, the convenience of the application of incremental methodologies (ILF, R-ILF, U-ILT) and other different approaches, such as Zbus, PR and PS, in a scenario with responsiveness at the demand side could be summarised in a set of results with advantages and drawbacks:

- The application of competitive locational marginal prices provided by an OPF analysis (ILF) sends appropriate economic signals to all market agents, yielding full-powered incentives for cost loss minimisation. However, these prices produce high price volatility and a considerable loss of social welfare as a result of overrecovery of losses. In other words, the monopolist (network provider) receives additional income owing to the cost overrecovery.

- The reconciled incremental procedure (R-ILF) almost recovers the entire power losses, thus producing less volatile prices. However, these procedures produce a slight increase power losses with respect to the competitive solution. 
- The application of U-ILF, Zbus, PS and PR approaches produces higher power losses and under-recovery of losses, reaching practically the same welfare level of the R-ILF approach. In other words, the monopolist (network provider) should pay power losses affecting his revenue requirement. This result implies that an arbitrary loss distribution (50:50\%) may originate from a cross-subsidisation condition, sending wrong economic signals without guarantee of revenue reconciliation of losses under the electricity market with elastic response at the demand side.

- Under reconciled incremental approaches (U-ILF and R-ILF), the slack-bus choice does not affect the social welfare. However, the U-ILF approach produces a higher underrecovery of losses.

\section{Conclusions}

A methodology for the assessment of the impact of different network-cost-loss-allocation methods under efficient energy markets is presented. From the regulatory viewpoint, the proposed methodology evaluates the effect of each network loss pricing policy on the market equilibrium point, taking into account the price elasticity of demand. The results indicate that Lagrange multipliers associated to an OPF solution become in the competitive prices that incentive efficiency on loss reduction. However, these prices lead to volatile behaviour and allocate approximately twice the power losses, inducing a loss of social welfare. Reconciled procedures such as incremental (R-ILF and U-ILF), pro rata (PR), proportional sharing (PS) and circuit based (Zbus) send scarce signals for loss reduction and may result in an under-recovery of losses. The best performance was achieved using a reconciled incremental procedure (R-ILF).

\section{References}

Bialek, J.W. (1996) 'Tracing the flow of electricity', IEE Proc-Gener., Transm., and Distrib., July, Vol. 143, pp.310-320.

Conejo, A.J., Arroyo, J.M., Alguacil, N. and Guijarro, A.L. (2002) 'Transmission loss allocation: a comparison of different practical algorithms', August, IEEE Trans. Power Systems, Vol. 17, No. 3, pp.571-576.

Conejo, A.J., Galiana, F.D. and Kockar, I. (2001) 'Z-bus loss allocation', IEEE Trans. Power Systems, February, Vol. 16, No. 1, pp.105-110.

De Oliveira-De Jesus, P.M. and Ponce de Leão, M.T. (2004a) 'Cost loss allocation in distribution networks with embedded generation: a fuzzy approach', Proc. of IEE MedPower2004, Limassol, November.

De Oliveira-De Jesus, P.M. and Ponce de Leão, M.T. (2004b) 'Impact of uncertainty and elastic response of demand in short term incremental prices', Proc. of PMAPS2004, Iowa, September.

Elgerd, O.I. (1982) Electric Energy Systems Theory, 2nd ed., New York: McGraw-Hill Book Co., pp.284-292.

Galiana, F.D., Conejo, A.J. and Kockar, I. (2002) 'Incremental transmission loss allocation under pool dispatch', IEEE Trans. Power Systems, February, Vol. 17, No. 1, pp.26-33.

Goméz Expósito, A., Riquelme Santos, J.M., Gonzales Garcia, T. and Ruiz Velasco, E.A. (2000) 'Fair allocation of transmission power losses', IEEE Trans. Power Systems, February, Vol. 15, No. 1, pp.184-188. 
IEEE APM Subcommittee (1979) 'IEEE Reliability Test System', IEEE Trans. Power App. Syst., November-December, Vol. PAS-98, pp.2047-2054.

Leite da Silva, A.M. and Carvalho Costa, J.G. (2003) 'Transmission loss allocation: Part I - single energy market', IEEE Trans. Power Systems, November, Vol. 18, No. 4, pp.1389-1394.

Lima, D.A. and Padilha-Feltrin, A. (2004) 'Allocation of the costs of transmission losses', Electric Power Systems Research, November, Vol. 72, No. 1, pp.13-20.

Nicholson, W. (1997) Microeconomic Theory, 7th ed., New York: The Dryden Press, pp.440-441, 558.

Salgado, R.S., Moyano, C.F. and Medeiros, A.D.R. (2004) 'Reviewing strategies for active power transmission loss allocation in power pools', International Journal on Electrical Power and Energy Systems, February, Vol. 26, No. 2, pp.81-90.

Schweppe, F.C., Caramanis, M.C., Tabors, R.D. and Bohn, R.E. (1988) Spot Pricing of Electricity, Boston, MA: Kluwer Academic Publishers.

Shrimohammadi, D., Filho, X.V., Gorenstein, B. and Pereira, M.V.P. (1996) 'Some fundamental technical concepts about cost based transmission pricing', May, IEEE Trans. Power Systems, Vol. 11, No. 2, pp.1002-1006.

Stoft, S. (2002) Power System Economics, Piscataway, NJ: IEEE - Wiley Interscience Publication, pp.424-428.

Weber, J.D. and Overbye, T.J. (1999) 'Modeling the consumer benefit in the optimal power flow', Decision Support Systems, March, Vol. 24, Nos. 3-4, pp.279-296.

Wood, A.J. and Wollenberg, B.F. (1996) Power Generation Operation and Control, Wiley-Interscience Publication.

Wu, F.F. and Varaiya, P. (1995) Coordinated Multilateral Trades for Electric Power Networks: Theory and Implementation, University of California Energy Institute, Power Rep. PWP-031.

\section{Appendix Network data}

Table 14 IEEE RTS 24-bus test system - demand equilibrium operation point

\begin{tabular}{|c|c|c|c|c|c|c|c|}
\hline \multirow{2}{*}{$\begin{array}{l}\text { Load } \\
\text { bus }\end{array}$} & $P^{\circ}{ }_{D}$ & $Q^{\circ}{ }_{D}$ & $\rho_{D}^{\circ}$ & \multirow{2}{*}{$\begin{array}{c}\text { Load } \\
\text { bus }\end{array}$} & $P^{\circ}{ }_{D}$ & $Q^{\circ}{ }_{D}$ & $\rho_{D}^{\circ}$ \\
\hline & $M W$ & $M V A r$ & $\$ / M W h$ & & $M W$ & $M V A r$ & $\$ / M W h$ \\
\hline 1 & 108.0 & 22.0 & 26.50 & 10 & 195.0 & 40.0 & 27.36 \\
\hline 2 & 97.0 & 20.0 & 26.51 & 13 & 265.0 & 54.0 & 27.00 \\
\hline 3 & 180.0 & 37.0 & 26.65 & 14 & 194.0 & 39.0 & 26.64 \\
\hline 4 & 74.3 & 15.0 & 27.54 & 15 & 317.0 & 64.0 & 25.55 \\
\hline 5 & 71.0 & 14.0 & 27.36 & 16 & 100.0 & 20.0 & 25.68 \\
\hline 6 & 136.0 & 28.0 & 27.89 & 18 & 333.0 & 68.0 & 25.01 \\
\hline 7 & 125.0 & 25.0 & 26.50 & 19 & 181.0 & 37.0 & 25.86 \\
\hline 8 & 171.0 & 35.0 & 27.72 & 20 & 128.0 & 26.0 & 25.79 \\
\hline 9 & 175.0 & 36.0 & 27.20 & - & - & - & - \\
\hline
\end{tabular}


Table 15 IEEE RTS 24-bus test system - producer cost structure

\begin{tabular}{|c|c|c|c|c|c|c|c|}
\hline \multirow{2}{*}{$\begin{array}{l}\text { Generator } \\
\text { bus }\end{array}$} & \multicolumn{2}{|c|}{ Cost function } & \multirow[b]{2}{*}{$P_{G}^{\max }$} & \multirow{2}{*}{$\begin{array}{c}\text { Generator } \\
\text { bus }\end{array}$} & \multicolumn{2}{|c|}{ Cost function } & \multirow[b]{2}{*}{$P_{G}^{\max }$} \\
\hline & $a$ & $b$ & & & $a$ & $b$ & \\
\hline & $\$ / M W h$ & $\$ / M W h^{2}$ & $M W$ & & $\$ / M W h$ & $\$ / M W h^{2}$ & $M W$ \\
\hline 1 & 24 & 0 & 192 & 16 & 21 & 0 & 155 \\
\hline 2 & 24 & 0 & 192 & 18 & 15 & 0 & 400 \\
\hline 7 & 26.5 & 0 & 300 & 21 & 15 & 0 & 400 \\
\hline 13 & 27 & 0 & 591 & 22 & 12 & 0 & 300 \\
\hline 15 & 21 & 0 & 227 & 23 & 24 & 0 & 660 \\
\hline
\end{tabular}

